\title{
Internships: The Nuts And Bolts Of An Effective Program
}

\author{
C. Kenneth Meyer, Ph.D., Drake University, USA \\ Sara Kurovski, Mayor of Pleasant Hill, IA; Manager of Sustainability for Kum \& Go, USA \\ Stephen E. Clapham, Drake University, USA
}

\begin{abstract}
Braxston Public Engineering and Consulting Group (BPECG) is a nationally known and respected company that is magnate for students who wish to receive a valued internship experience. Under the able direction of Amy Greene, the work experiences were coordinated during the summer and interns were well paid for their contributions. The case study chronicles the trials and tribulations faced by a competent, highly energized engineering intern who faces the malaise of an organization that is unprepared to provide a valid learning experience. As the case unfolds, Greene has an Eureka experience and learns from a colleague how interns can and do make vital contributions (ROI's) to their assigned organizations. Upon reviewing the contributions that interns made in three organizations, she redesigns Braxston's Internship program, reviews the State University Intern to Work Program that addresses, among many other factors, the internship purpose, supervision, learning objectives, and intern and employer obligations. The case includes an Intern Evaluation form and a Memorandum of Understanding (MOU) between the university and the company. Last, the Questions and Instructions provide for focused discussion and analysis and the references enable learners to research the top internship programs in the United States.
\end{abstract}

Keywords: Internships; Problem Based Learning; Experiential Learning; Internship Assessment and Evaluation; Internship Goals and Objectives

\section{INTRODUCTION: MAKING INTERNSHIP EXPERIENCES COUNT}

$\mathrm{t}$ was Amy Greene's favorite day of the year, the day the summer interns started work at the Braxston
Pubic Engineering and Consulting Group (BPECG) where she had worked for the past five years. This
year, Amy was charged once more with overseeing the experiences that the interns would receive. BPECG was a respected engineering company in the area and received numerous applications from engineers from across the country who sought employment there. BPECG was an obvious draw for those engineering students who wish to launch their careers in a prestigious firm with a national reputation.

This year, Amy would supervise the interns selected to work at her company - interns who were by objective standards among the best and the brightest students at the neighboring major state universities. To be selected as a Braxston intern was a special honor since the company had a very competitive program and was able to choose from a stable of extremely qualified applicants.

The interns placed at BPECG worked during their summer vacations, were paid fifteen dollars an hour, and were expected to work at least 40 hours per week. In turn, the interns received college credit (three hours) for their experience and were required to write a paper that detailed what they did and how it contributed to their learning in their specific field of engineering-- mechanical, electrical, environmental, or chemical. In anticipation of her new "study" Amy had saved up a host of things to do and projects to be completed for her new charges.

\section{CHRISTINA KIMBALL'S BEGINNING INTERNSHIP EXPERIENCE}

Christina Kimball received one of the prized internships at BPECG. She was excited and nervous when she came to engineering office and knocked on Amy's office door. It seemed like minutes had gone by before Amy looked up from what she was doing and acknowledged her. She felt so awkward just standing in front of an open door and not 
being "properly" received. After five or so seconds had elapsed, Amy slowly turned toward the door, and looking up she said, "You must be my intern for the summer." Assertively, Christina stepped forward and courageously said: "My name is Christina and I'm so ex--" but before she could finish, Amy interrupted her.

"That's great," Amy somberly said, looking back down to what she had been reading. "Your cubicle is around the corner and there's a stack of files. You need to make two copies of each file, mail one to each of the clients that is listed on the letter and file the other one. It should take you about two days to do that. Take your half-hour lunch break whenever you would like."

Christina exited Amy's office quickly, determined to impress her "boss" and ready to get her task done in less than the expected two days. Christina had heard rumors from other interns that they did not get to do actual engineering work when interning at Braxston, but she was going to be different and she knew the value of having BPECG's name on her resume. Delighted by her selection, but not surprised since she was the top student in her class, she was anxious to get some "applied experience" and then move on to graduate. But now, she had to get through this summer internship. She figured that during the first week she would do some assistant type activities and then after that she would get to work on some small projects. After Christina got settled into her cubicle, she quickly began working on the large stacks of files that swamped her desk.

Four weeks later Amy was humming to herself as she entered her office; she spotted Christina at her cubicle, "Is my coffee on my desk?" "Yes ma'am," Christina responded.

It had been nearly a month and Christina was still doing pedestrian kinds organizing, filing, and "light housekeeping" activities such as getting coffee for Amy, faxing papers, making copies, pulling files, running to the post office to purchase supplies and mail items, and even putting all of the books and manuals in Amy's office in alphabetical order. She was beginning to wonder if she could stand to spend a summer doing such routine and monotonous errands - after all, she mumbled to herself, "I am well on the way to becoming an engineer and would like to have some experience on an actual project. This internship has become so boring. Why can't I at least proof a plan or a report, or something that would use my skills and talents?"

\section{WHAT ARE INTERNSHIPS ALL ABOUT? A EUREKA MOMENT}

Later that day Amy went to lunch with a fellow colleague. Sam was one of the lead engineers at a manufacturing plant in the area. As friends, they tried to get together every once in a while to catch up and brag about the projects that they could showcase. Amy sat and waited for Sam for 15 minutes before he arrived for their luncheon date. "I was beginning to think you forgot," Amy said in an annoyed voice. "Sorry, my summer intern was giving a presentation to the team about his project. He has so many ideas and concepts that we all lost track of time," Sam replied.

"What, on how to make copies more effectively?" Amy responded sarcastically. "No," Sam replied sharply. "He is from the Department of Natural Resources Pollution Prevention Intern Program. Some of his ideas are going to save us big bucks in the long run." Sam went on to explain how her company had applied to have an intern work for his firm. The intern's job was to first monitor how the company operates and then evaluate the processes used in terms of solid waste reduction, hazardous waste reduction, water conservation, water quality reduction or improvement, air quality improvement, energy reduction, and greenhouse gas emission reduction. "When our intern presented today, he had pinpointed the areas we could "cut some fat" out of our operations, what the upfront costs would be to implement some of the ideas, how long it takes to realize some cost savings, and how much we could save in the long run! He is going to benefit our company greatly - it's simply amazing! Not to mention we will have a much better impact on the environment. Imagine, an intern saving us hundreds of thousands of dollars over the course of a year."

Amy sat and pondered what Sam was telling her during the rest of the lunch. Sam noticed that Amy seemed distracted, but did not comment on her inattentiveness. By the time Amy arrived back at her office, she realized how much money she was potentially costing BPECG by not allowing her and the other summer interns to excel in those 
areas where they had knowledge and interest. She went straight into her office and shut the door, and once more examined the resumes of the selected interns, beginning with Christina's.

\section{MEASURING INTERN CONTRIBUTIONS AND SUCCESSES: SAVORING SUCCESS}

As she went through the "Pollution Prevention Intern Program Case Summaries" that the Department of Natural Resources (DNR) representative left with her, she was astonished to see how the interests and skills of the engineering students had been properly matched with the organizational needs of diverse organizations drawn from the three economic sectors (private, public and non-profit). Amy found the metrics used by the DNR and EPA in assessing the impact which the interns had on the sponsoring organizations particularly intriguing. Of course, the interns had a firm grasp on the types of problems they were prepared to research since they were advanced undergraduate engineering students from colleges and universities within the state and they personally wanted to make a difference in the general areas of economic and environmental sustainability. Specifically, they understood that they would be gaining real-life, hands-on, experiential based knowledge—not just serving as office "handypersons," as they went about their business of research and making recommendations that would improve the efficiency of operations and industrial processes.

As Amy read through the intern report, she was flabbergasted to learn that the cumulative savings realized from the intern recommendations in the areas of waste reduction (hazardous and solid), water conservation, and reduction/diversion of air pollutants and greenhouse gases, etc. was much higher than she could ever have imagined - $\$ 1,279,642$. She also read with eagerness about the ten year history of actual savings (2001-2009) from the internship program and could hardly believe that $\$ 58,653,401$ had been realized through cost saving measures recommended by the engineering students. In terms of reduction in water use alone, over one billion gallons had been realized and in the area of waste management, nearly 320 tons had been averted from the waste stream including over one million gallons of hazardous waste. Further reduction was found in mercury abatement $(48,812$ grams) and energy use in KWH $(258,669,685)$ and in THERMS $(16,576,117)$. Last, the intern recommendations for 2009, in tons of air pollution diverted for SO2 (103), CO (282.27), NOx (206.98), VOC (15.51), and PM (78.04) were acknowledged. In terms of greenhouse gases (GHG) diverted in tons the numbers were equally impressive: $\mathrm{CO} 2(23,766), \mathrm{CH} 4(9,061), \mathrm{N} 2 \mathrm{O}(3,987)$ and CFC $(344)$.

She was anxious to learn more about some of the actual student projects and see how the interns contributed to pollution prevention, abatement and reduction, the types of waste streams reduced, and improvements they made on lowering operation costs. She singled out three projects that had been researched in public and non-profit organizations. She felt that if net efficiencies could be achieved in these sectors, it would be much easier to identify cost and energy saving measures in manufacturing and industrial environments.

Allen Memorial Hospital (AMH): An 85 year old hospital with about 820,00 square foot structure that cared for about 50,000 patients a year. AMH was like other hospitals in the state and produced vast amount of solid waste. The chemical engineering student, Meredith, was charged with reducing biohazard waste and conducting other waste management assessments. In the final analysis, she found that 13 percent of the waste stream was made of regulated medical waste - not the 3-5 percent suggested by the Centers for Disease Control and Prevention (CDC). She found innovative ways to reduce the stream by 38 percent and save the hospital $\$ 25,177$ yearly: education of clinical staff, location of biohazard containers, and instructive signage. Also, she found ways to produce electrical savings by replacing incandescent bulbs with fluorescent ones and the use of LED exit signs. Further, she introduced a solvent recycling system that cut the cost of purchasing and disposing of xylene by 95 percent - a hazardous waste. The biohazard waste reduction plan that she developed will save AMH about $\$ 25,000$ annually.

The City of Pella, Iowa: This city has operated its own municipal coal fueled power plant since 1911 and generated about $38 \mathrm{MW}$ on site, augmented by $28 \mathrm{MW}$ produced in its adjacent diesel powered plant. Andrew, a mechanical engineering student, assessed the performance level of the plant and analyzed ways that would produce water and chemical savings in the cooling and boiling operations. In an effort to reduce pollution, save energy, and reduce water consumption, he recommended boiler upgrades, variable frequency drives (VFD) for pumps and fans, cogeneration (biomass from adjacent manufacturing facilities), lighting upgrades, evaporator replacement, and insulation programs. The lighting upgrades will produce about $\$ 16,000$ in annual savings for the city and if the 
cogeneration plan was implemented, the city would save approximately $\$ 829,000$ a year.

Nebraska Medical Center (NMC): The Nebraska Medical Center is located in Omaha and is the largest hospital in the state. It has 14 buildings with two million square feet of space. It has a staff of 5,000 that complements 1,000 physicians. David, a mechanical engineering intern, assessed the way energy use could be reduced and found that a savings of $\$ 39,400$ or a $695,400 \mathrm{KWH}$ reduction could be realized on a yearly basis. Simply, T12 fluorescent bulbs were replaced with T8 fixtures, and by making changes that improved the lighting adequacy in hallways, offices and, among other areas, examination rooms, cost savings could be realized. By the replacement of older fluorescent technologies with new ones (T8), maintenance and inventory costs, as well as energy costs were sharply cut, in some instances up to 50 percent.

Amy had just had an "aha!" moment. Her idea of a successful internship experience had drastically changed. Under her direction, Amy created a work team and charged it with developing a plan outlining what interns might be assigned to do during their time at Braxston. For the first time, she solicited suggestions and ideas from the other lead engineers, interns, and other Braxston employees. She was on a mission to create a program that would not only provide a genuine, valuable engineering internship experience for the student, but one that would provide a healthy Return on Investment (ROI) for the Braxston Group.

\section{AUTHOR BIOGRAPHIES}

C. Kenneth Meyer (kenneth.meyer@drake.edu) is Thomas F. Sheehan Distinguished Professor of Public Administration, Drake University. He previously held teaching positions at Winona State University, State University of New York, University of South Dakota and the University of Oklahoma, Norman, Oklahoma. He has nearly 300 published case studies that appear in numerous venues. His latest books are entitled: Managing People as Assets; Human Relations in Action; Managing America's Organizations; and Managing Public Service Organization; Conducting the People's Business; and Organizational Change. His newest book is entitled Nonprofit Management and Leadership Case Studies (2014). (Contact Author)

Sara Kurovski is the Mayor of Pleasant Hill, Iowa and also the Manager of Sustainability for Kum \& Go. She earned her Master's in Public Administration from Drake University and her undergraduate degree in Communication Studies from Truman State University. She spends most of her 'free' time serving on different boards and commissions in Polk County, Iowa.

Stephen E. Clapham (steve.clapham@drake.edu) is a professor of management in the Drake college of Business and Public Administration. He earned his Ph.D. from Indiana University. He has published research in the areas of trust, ethics, strategic planning, organizational voice, and impression management.

Recommended Courses: Introduction to internship experience, applied management, experiential learning, educational assessment and evaluation, business internship, public management internship

\section{SUGGESTED REFERENCES}

Guidance for Hiring Interns. (2011, December 6). Forbes Magazine.

http://www.internships.com/employer/resources/setup/benefits

http://internships.about.com/od/internships101/a/ Why-Should-You-Hire-An-Intern.htm Why Hire Interns?

http://www.techrepublic.com/blog/career-management/infographic-why-should-companies-hire-interns/

$\mathrm{http} / /$ www.businessinsider.com/companies-with-the-best-internships-glassdoor-2013-2?op=1\#ixzz38oBkaSAJ

Rosen, Andrew G. (2011, January 11). Why You Should Hire Interns for Your Office, US News and World Report.

Should You Use Unpaid Interns. (2013, February 22). Time Magazine. 


\section{QUESTIONS AND INSTRUCTIONS}

1. Analyze the abbreviated Internship Handbook which appears in Exhibit 1. Please note that it includes a component that deals with an introduction to undergraduate and graduate internship programs based on several guidelines provided by the national Association of Schools of Public Affairs and Administration (NASPAA); purposes of the Internship Program; the administration of the internship program; the academic component; placement of interns; work scheduling and hours; intern supervision; integration of interns into the organizational culture; intern and employer obligations; compensation; and internship evaluation.

2. Please examine the Intern Evaluation Form (see Exhibit 2) and determine if any additions, deletions or modifications are required. If so, please prepare an alternative form that you believe would more effectively evaluate the internship experience. Please discuss this form with members of your agency or department and based on their experiences with supervising and evaluating internship experiences, obtain their feedback.

3. A Memorandum of Understanding (MOU) is normally entered into between the academic institution and the partnering organization for a formal internship program (see Exhibit 3). Once more, examine the MOU and indicate if it has any deficiencies that should be addressed. Also, indicate those aspects of the MOU which you believe will add to the overall quality of the internship experience. Please be specific.

4. According to Glassdoor (social jobs and career community), the best internship programs for 2014 were, in order: Facebook, Google, Qualcomm, Schlumberger, Epic, Intel, Microsoft, Bloomberg, Apple, and Exxon Mobile. Please examine at least five of these nationally ranked organizations and determine what makes them the best in the United States. Pay special attention to how interns as employees are treated; the development of cohesion within the organization; and, the assignment of specific projects and the way mentorship is conducted.

5. After reviewing Exhibits 1, 2, and 3, please prepare an internship or field experience for your own organization. The internships presented in the case study deal with the technical application of engineering principles to organizational processes and activities. However, given the background of students majoring in public administration, public affairs, and public policy, what kind of valid learning experiences would you be able to develop in your agency or department? Please be specific. Please discuss the prospects of having a welldeveloped internship program with others in your organization. Next, map out a plan that presents an intern description, including application and selection criteria, work/project assignment and supervision responsibilities, and among other components, a final organizational report. You may wish to include additional factors that would make up your "model of an idealized internship program." Please be specific. 
Exhibit 1. The State University Intern to Work Program*

\section{The State University Intern to Work Program}

Universities and colleges that grant degrees in public administration and related fields (political science, management, sociology, etc.) usually require that students obtain practical field experience in one of the three sectors (public, non-profit, or private) prior to graduation. The actual experiential component is usually called an internship or field experience.

Over the years, State University has drawn upon the philosophy, methods, and language of many internship programs in other colleges and schools, departments and programs in public affairs and administration, as well as academic and professional materials. Our aim is to provide prospective interns and intern supervisors in these different sectors with an overarching view of those orientations and practices which should guide our graduate and undergraduate experiential learning programs.

\section{Internship Purpose}

The mission of the department is to bring "... the world into the classroom and classroom into the world." This can be done through a variety of experiential learning programs, especially an internship, in which students gain realistic exposure to complex, formal organizational and bureaucratic environments. This experience assists in developing an awareness of the internal dynamics of an agency or department and of the values and attitudes of its employees regarding their clients, superiors, and team associates. Thus, the internship becomes an essential component of the public service student's professional and academic education - a major building block in the formation of a professional degree.

State University's internship program provides a structured introduction to a practical learning experience. Throughout the experience, the student gets acquainted with "hands-on" work activities in a supportive learning environment. As such, the internship provides a needed bridge between the world of academia and the applied world of the public administrator. Students who have garnered such an experience are better able to assess which personal competencies they need to improve upon or develop - especially for those who have not worked in a major agency or department in one of the sectors.

The internship relationship is equally important in so far as the student, university and supporting agency all benefit from the experience. In brief, a collaborative, reciprocal, and mutually beneficial relationship is established between all those involved in the internship program. Interns bring to the program a comparatively high level of general skills in management, policy, methods of analysis, statistics, and economic and financial understandings. In an augmentative manner, the internship provides the sponsoring agency with a chance to diversify the mixture of its staff and assign research and evaluation projects that ordinarily might not be accomplished. The internship supervisor also interacts directly and regularly with the intern and becomes a participant in preparing future public managers in the complexity and uncertainty of competing values and roles which public administrators often find themselves.

For the department and university, the internship provides a critically important link to the professional community. The experiential learning program contributes to the overall quality of the educational experience at State University and establishes a connection between the academic department (professors and students), and managers/analysts in their effort to jointly provide a meaningful learning experience and actually use the "...world as a learning resource."

\section{Internship Supervision}

Supervision, coaching and mentoring of the internship involves the agency manager and the internship coordinator from State University. Normally, the agency supervisor is designated by the sponsoring agency and is responsible for making work assignments, evaluating the work products/reports of the intern, and assessing the progress which the intern is making. The agency supervisor is asked to serve as a mentor or coach and discuss with the intern the 
essential factors associated with different management strategies and assessment approaches associated with the assigned duties and projects. It is expected that the intern will become, as more experience is acquired, a fullyfunctioning member of the sponsoring agency, and exercise a modicum of leadership, decision-making, and managerial skills. Once more, a joint relationship should be established between agency manager and internship so that in a spirit of "trust and confidence," a mutual assessment of one-another can take place and they can both develop an awareness of the knowledge, skills and abilities, of the intern and degree to which administration discretion and responsibility might be properly delegated. Of course, this process takes time and as the manager, intern and internship coordinator evaluate the experiential knowledge gained and the maturity developed.

This supervisory relationship is the lynchpin of the internship program. It requires the creation and maintenance of a reliable and regular open channel of communication between the three parties (intern, supervisor, and coordinator). Mutual interests and expectations must be candidly discussed along with making regular assessments of the progress and problems, if any, in the performance of the individual tasks (assignments) and projects which the intern is performing. In this type of open, honest communication and trusting environment, the intern may be most appropriately monitored and evaluated and the capabilities and limits of the intern established. After all, the intern is in the program to gain a valuable learning experience and be appropriately supervised and evaluated. Although there is no single best way to manage interns, there is a balance that can be established between near-continuous, close supervision or monitoring of all activities to virtual absence of guidance and supervisory attention to daily activities. It is advisable to establish joint goal-setting meetings between the intern and agency manager so that a discussion of the learning and performance objectives can be discussed and evaluated. These meetings should be followed by periodic regular work-progress reviews and an in-depth exit interview at the conclusion of the internship.

Since the intention of the internship is educational in nature, the agency is encouraged, to the extent possible and practical, to conduct an orientation session similar to the orientation given new hires, in which the intern is introduced to persons with whom they will be working (administrative support personnel) and a historical overview of the agency and its objectives. It is important to include the intern in all meetings related to the assigned activities and areas of responsibility. This requires that the intern becomes a recognized member of the work group and has the needed resources (facilities, desk, computer, etc.,) to do their work.

\section{Learning Objectives}

Interns are expected to prepare statements of learning objectives at the beginning of their experience. These objectives should be mutually developed and agreed upon by the agency manager, internship coordinator and the intern. They become essential in providing a structure and in assessing the progress that the intern is making. The performance objectives that are developed will specify what the intern will do on the job and also form a basis for internship evaluation at the conclusion of the experience. The mutual understandings associated with this collaborative process are essential to the success of the experiential learning process. In brief, the learning objectives should identify what the intern is expected to be able to do as a result of the internship experience; address how the intern expects to acquire the knowledge, skills, or abilities identified as an objective; and how the intern will acknowledge and demonstrate that the objective(s) have been accomplished. These statements (objectives) should be precise, specific and unambiguous. Verbs such as write, identify, state, solve, and compare, are preferable to appreciate, familiarize and understand. Once the learning objectives and performance objectives are prepared and jointly agreed upon, the means by which they will be accomplished may be specified. For example, if one of the intern's learning objective is to be able to identify the allocation of human and financial resources in the agency, then, the intern and agency manager will jointly determine how this can be best accomplished (e.g., inspection of the budget, position allocation statement, conversations with agency administrators, etc.).

Additionally, as mentor, the agency manager should provide frequent feedback regarding the intern's job performance. This may take the form of informal comments and observations or the supervisor may schedule one or more work-progress review with the intern to serve as a helper, coach or facilitator. At the third or fourth week of the internship it is recommended that a joint meeting be scheduled between the intern and agency manager at which time the intern's learning and performance objectives are reviewed and assessed. At this time, the intern should be encouraged to discuss any performance problems that might be present and provide the supervisor with a selfassessment of the progress which is being made toward meeting the agreed upon learning and performance 
objectives. Periodically, during the internship, these joint meetings should be scheduled in which progress is assessed and administrative strengths and deficiencies can be addressed. At these meetings it is appropriate to also discuss career options and developmental strategies.

\section{Intern and Employer Obligations}

There are a few essential intern obligations that must be met:

1. Secure the agency manager's and intern coordinator's consent to beginning and ending dates, hours of work, and vacations;

2. Develop written learning and performance objectives for the internship experience;

3. Perform the duties required by the employer in a responsible, professional and timely manner;

4. Evaluate the job experience in terms of the benefits and learning acquired; and

5. Complete the academic component of the internship program.

Employers are asked to:

1. Provide conscientious supervision (mentoring and coaching) and developmental consultation and communication;

2. Assist the intern in the development of learning and performance objectives;

3. Provide work experience that is appropriate to the preparation and sophistication of the intern and calculated to realize the intern's learning objectives;

4. Provide the intern with a constructive discussion of the intern's learning objectives and complete an exit interview upon the completion of the internship; and

5. Provide a written evaluation of the intern's performance, including recommendations for job performance and personal growth and development 
Exhibit 2. Intern Evaluation Form*

\section{Intern Evaluation Form}

Instructions: Using the form below, please provide an evaluation of the student who interned with your organization. The intern should be compared with other students of comparable academic level, with other personnel assigned the same or similarly classified jobs, or with individual standards (whichever you agreed upon). This information will assist the coordinator of the Professional Intern Program in determining the overall effectiveness of the internship experience and in grading the intern for academic credit. The department greatly appreciates your cooperation and assistance in this matter and this type of experience could not be provided if organizations like your own did not participate in the program.

A stamped, addressed envelope is provided for your convenience in returning this evaluation. If you have any questions, comments, or suggestions, please email or call me and I will immediately respond.

Part I: Ability and Application

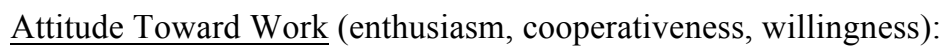

( ) enthusiastic; outstanding cooperation; tries new ideas; responds readily to constructive criticism

( ) responsive; cooperates well; meets others more than half-way; responds to constructive criticism

( ) usually cooperates; does not resist new ideas or constructive criticism

( ) uncooperative; resents new ideas and constructive criticism; displays little interest

Dependability (willingness to accept responsibility; to follow through):

( ) outstanding ability to perform with little supervision

( ) willing and able to accept responsibility; little checking required

( ) usually follows instructions; normal follow up

( ) refuses or unable to carry responsibilities; needs constant follow up

Quantity of Work (output of work; performance speed):

( ) works consistently and with excellent output

( ) works consistently with above average output

( ) maintains group average output

( ) below average output; slow

Writing Skills (organization, grammar, usage, punctuations, sensitivity to audience):

( ) outstanding

( ) above average

( ) average

( ) below average

( ) no opportunity to observe

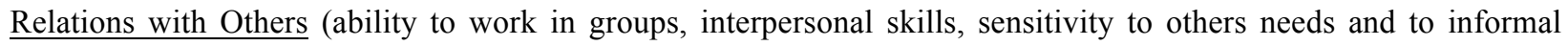
norms of the office):

( ) exceptionally well accepted; fits in, advice is sought

( ) works well with others

( ) gets along satisfactorily

( ) has difficulty working with others

( ) works very poorly with others 
Initiative (ability to exercise self-reliance and enterprise):

( ) grasps situation and goes to work without hesitation

( ) works independently often; seldom waits for others

( ) usually waits for instructions; follows others

( ) does only what is specifically instructed to do

Quality of work (accuracy and effectiveness of work; freedom from errors):

( ) consistently good quality; errors are rare

( ) usually good quality; few errors, lateness

( ) passable work if closely supervised

( ) frequent errors; cannot be depended upon to be accurate

Attendance (reliability to be on the job):

( ) always can be relied upon to be at work on time; absent only when real emergency

( ) usually can be relied upon to be at work on time; explained absences occur occasionally

( ) comes in late with reasonable excuses; fairly frequent explained absences

( ) frequent unexplained lateness and/or absences

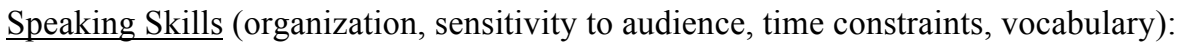
( ) outstanding
( ) above average
( ) average
( ) below average
( ) no opportunity to observe

Job Knowledge (technical knowledge of job; ability to apply it):

( ) knows job thoroughly; rarely needs help

( ) knows job well; seldom needs help

( ) knows job fairly well; requires instructions

( ) little knowledge of job; requires constant help 
Part II: Summary Evaluation

A. Is this intern the type of employee you would consider hiring if he/she interviewed for a position?
( ) yes, definitely
( ) no, probably not
( ) not certain
( ) yes, possibly
( ) no, definitely not

B. If this intern were your student, what letter grade would you award for his/her work performance? _...........D...........B.....A.....

C. Would you care to add any additional comments or observations concerning the job performance of the intern?

D. What comments or observations would you care to make concerning the developmental needs of the intern if he/she is to be an effective manager?

(Please print)

Name of Intern: Date Completed:

Name of Supervisor:

Job Title:

Agency or Organization:

Signature: 
Exhibit 3: Memorandum of Understanding (MOU) for State Professional Intern Program

Memorandum of Understanding (MOU) for State Professional Intern Program

Professional Intern Program

Department of Public Administration and Public Affairs

Date

Student's Name Phone

Address City, State, Zip

Employer Internship Title

Intern's Site Supervisor \& Title

Faculty Sponsor Department Phone

Beginning Date Completion Date

Hours per week Work Schedule

If credit is desired, Course Number \& Title Credit Hours

Intern's Major Responsibilities:

Learning objectives (be specific):

Academic Requirements (journal, papers, reports, readings, meeting with faculty):

Evaluation by faculty sponsor will be based on:

Type of supervision (daily, scheduled conference, conference as needed, or...):

Service training and/or orientation to be provided by employer:

Additional conditions agreed to: 
General Responsibilities of Intern and Coordinator

A. The student agrees to comply with the policies of the employing organization, to attend all required orientations, in-service and staff meetings.

B. The student will notify his/her work supervisor if unable to work as scheduled.

C. The employer agrees to provide the student with orientation and supervision necessary to carry out the above specified responsibilities.

D. The internship will not be terminated before the specified date by either the student or employer until the faculty sponsor has been notified.

This memorandum has been reviewed and agreed to by:

Student Date

Faculty Sponsor Date

Supervisor Date

Each of the above will be provided with a copy of this agreement. The original will be kept on file in the Department of Public Administration and Public Affairs.

If major changes are made in any of the intern's responsibilities, student objectives, or academic requirements, all participants, including the Department of Public Administration and Public Affairs, must be notified in writing.

* Exhibits 1, 2 \& 3 were created, developed and modified for instructional purposes, and adapted from sample internship handbook: College of Business and Public Administration, Drake University, Des Moines, IA 
Internship: The Nuts and Bolts of an Effective Program

Student Name:

\section{Case Log and Administrative Journal Entry}

\section{Case Analysis}

Major case concepts and theories identified:

What is the relevance of the concepts, theories, ideas and techniques presented in the case to that of public management?

Facts - what do we know for sure about the case? Please list.

Who is involved in the case (people, departments, agencies, units, etc.)? Were the problems of an "intra/interagency" nature? Be specific.

Are there any rules, laws, regulations or standard operating procedures identified in the case study that might limit decision-making? If so, what are they?

Are there any clues presented in the case as to the major actor's interests, needs, motivations and personalities? If so, please list them. 


\section{Learning Assessment}

What do the administrative theories presented in this case mean to you as an administrator?

How can this learning be put to use outside the classroom? Are there any problems you envision during the implementation phase?

Several possible courses of action were identified during the class discussion. Which action was considered to be most practical by the group? Which was deemed most feasible? Based on your personal experience, did the group reach a conclusion that was desirable, feasible, and practical? Please explain why or why not.

Did the group reach a decision that would solve the problem on a short-term or long-term basis? Please explain.

What could you have done to receive more learning value from this case? 


\section{NOTES}

